\title{
The effect of neurofeedback on reduction symptoms of Attention Deficit and Hyperactivity Disorder: a meta-analysis study
}

\author{
Seyed Morteza Ziabakhsh ${ }^{1}$, Masoud Sharifi ${ }^{2}$, Jalil Fath Abadi $^{3}$, Vahid Nejati ${ }^{4}$ \\ 1-PhD Student of Educational Psychology, Department of Psychology, Shahid Beheshti University, Tehran, Iran. \\ 2-Assistant professor, Department of Psychology, Shahid Beheshti University, Tehran, Iran (Corresponding \\ Author). \\ E-mail: m-charifi@sbu.ac.ir \\ 3-Associate Professor, Department of Psychology, Shahid Beheshti University, Tehran, Iran. \\ 4- Associate Professor, Department of Psychology, Shahid Beheshti University, Tehran, Iran.
}

Received: $17 / 02 / 2020$

Accepted: 04/04/2020

\begin{abstract}
Attention Deficit Hyperactivity Disorder (ADHD) is known to be the most common childhood disorder. On the other hand, neurofeedback has been well received as a non-invasive treatment. The aim of this study is meta-analysis of researches conducted to investigate the effect of neurofeedback in reducing attention deficiency disorder with a focus on Iranian researches. Research method was meta-analysis, so all research reports have been found and gathered using domestic databases. The sample consisted of ten studies done from 2016 to first half of 2019 all around the country (Iran) including 1118 subjects. Results of these 31 studies have been metaanalyzed for model of fixed effects using effect size of standardized mean difference or d Kuhn (1988; Hooman, 2008). All statistical operations were performed using 2nd edition of Comprehensive meta-analysis software (CMA). Results showed that mean of overall effect size of reviewed studies is 0.574 for fixed effects model and 1.214 for random effects that both are significant in $\mathrm{p}=0.0001$ level. Non pharmacological treatments in sessions and lower ages can improve and reduce symptoms of attention deficiency and hyperactivity disorder.
\end{abstract}

Keywords: Neurofeedback, Attention deficiency disorder, Meta-analysis

How to cite this article : Ziabakhsh SM, Sharifi M, Fath Abadi J, Nejati V. The effect of neurofeedback on reduction - symptoms of Attention Deficit and Hyperactivity Disorder: a meta-analysis study. Shenakht Journal of Psychology and Psychiatry. 2020; 7 (2): 64-78 .URL: http://shenakht.muk.ac.ir/article-1-859-fa.pdf

Copyright (C) 2018 the Author (s). Published by Kurdistan University of Medical Sciences. This is an open access article distributed under the terms of the Creative Commons Attribution-Non Commercial License 4.0 (CCBY-NC), where it is permissible to download, share, remix, transform, and buildup the work provided it is properly cited. The work cannot be used commercially without permission from the journal. 


\title{
تأثير نوروفيدبك در كاهش علائم اختلال نقص توجّه و بيشفعالى: يك مطالعهُ فرا تحليل
}

\author{
سيد مرتضى ضياء بخش'، مسعود شريفى'، جليل فتح آبادى'، وحيد نجاتى ' \\ ا.دانشجوى دكترى روانشناسى ترييتى، كروه روانشناسى، دانشكاه شهيد بهشتى، تهران، ايران.

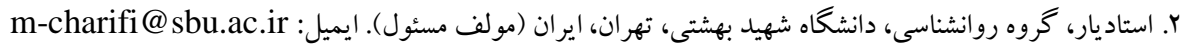

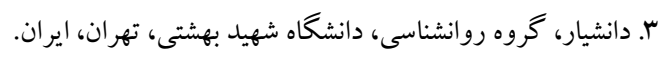

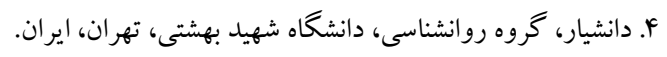

تاريخ بذيرش مقاله: 1/19/. 1\%99

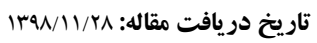

جكيده

اختلال نقص توجه و بيش فعالى، بهعنوان شايعترين اختلال دوران كودكى شناخته شده است از سوى ديخر نوروفيدبك به عنوان يكك روش درمانى غير تهاجمى بخوبى مورد استقبال قرار كرفته است

هدف يزوهش حاضر فراتحليل بزوهشهاى انجام شده در مورد تأثير نوروفيدبك در كاهش اختلال نقص توجه با تأكيد بر بزوهشهاى

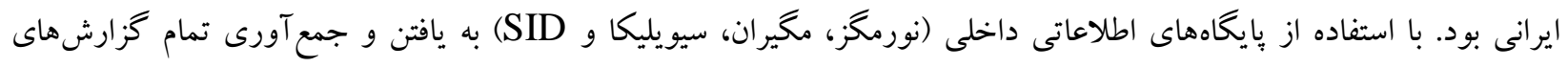

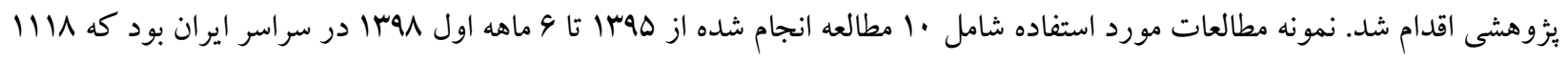

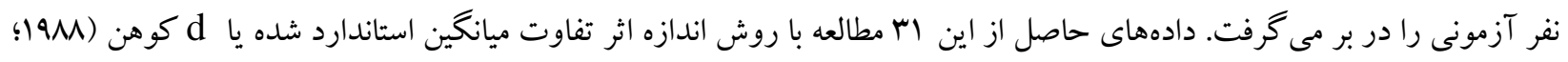

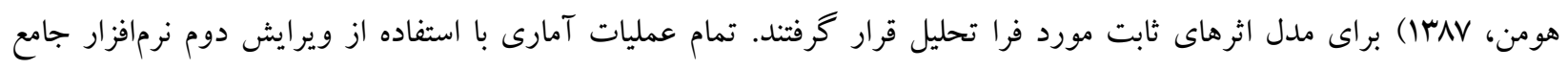

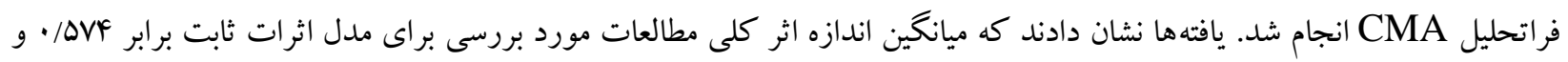

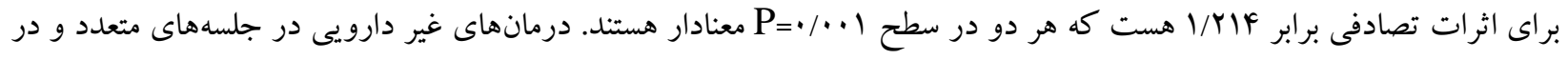
سنين بايين مى تو اند نشانهاى اختلال نارسايى توجه/بيش فعالى افراد را بهبود ببخشيد و كاهش دهد. كليدوازهها: نوروفيدبك، اختلال نقص توجه، فرا تحليل 
بودند (استوربوو همكاران، ها •Y)؛ اما مطالعاتى نشان مىدهند كه استفاده طولانى مدت از دارو درمانى، بروز عوارض جانبى احتمالى ناشى از دارو درمانى (مولينا و

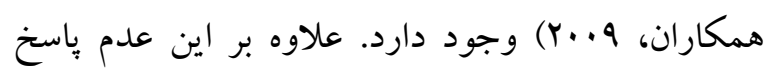

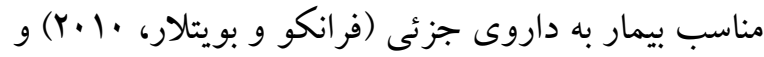
زمان و صرف هزينه زياد در استفاده از درمان هاى تركيبى به دليل درگيرى جندين متخصص (دالى و ورئ همكاران، Y..VI)، از ديخر معايب دارو درمانى قلمداد شده است. در راستاى توسعه درمان هاى غير دارويى اختلال نقص توجه / بيشفعال در سالهاى اخير، نوروفيدبك يكى از رويكردهاى به كار رفته در درمان اختلال نارسايى توجه / بيشفعالى است كه مؤثر بودن آن در حوزه نارسايىهاى تحولى بلهيزه اختلال نارسايى توجه/ بيشفعالى مجادله هايى را به وجود آورده است

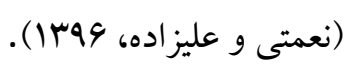

نوروفيدبك مبتنى بر يك رابط مغز و كامييوتر ( است و توسط يكك سيستم نرم افزارى و يكك خط لوله يردازش، در مجموع از ينج عنصر تشكيل شده است

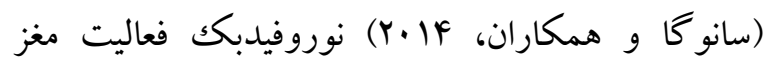
شركت كننده را كه از قبل بردازش شده است، اندازه كيرى مى كند. يارامترهاى از بيش انتخاب شده مغز (باند فر كانس خاص يا يتانسيل مغزى) بهصورت آنلاين محاسبه مىشوند و به سيخنالهايى ترجمه مىشوند كه در لئاسي زمان واقعى به كاربر برگردانده مىشوند؛ بنابراين،

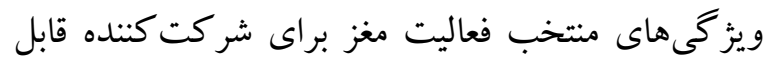
درك است. از طريق اين بازخورد، شركت كننده مىتواند

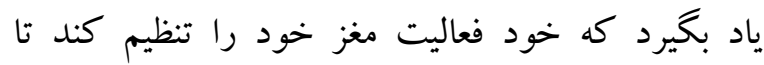

مقله

اختلال نقص توجه/ بيشفعالى ' اختلالى عصبى-تحولى

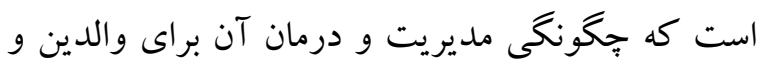
نيز متخصصان حوزه نارسايىهاى تحولى جالشانكيز بوده است (نعمتى و عليزاده، و4M ا) كودكان داراى اختلال نقص توجه / بيش فعالى سطوح نامناسب رفتار بيش فعالى، تكانشى و بى احتياطى را از لحاظ رشدى نشان

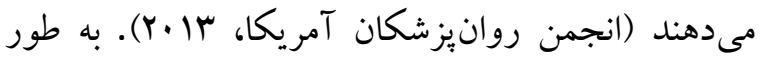
سنتى، درمان اختلال نقص توجه / بيش فعال شامل دارو درمانى است كه اغلب توسط رفتار درمانى مبتنى بر

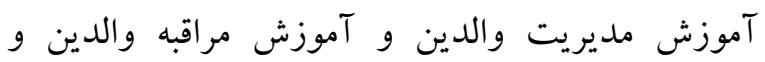
معلمان تكميل مى شود (تيلور و همكاران، F +..Y). علاوه

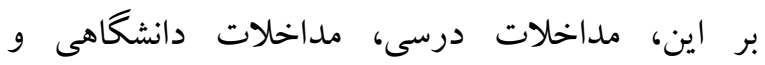
مداخلات مربوط به همسالان به عنوان رويكردهاى درمانى روانشناختى مورد استفاده قرار مى گيرند (دالى و همكاران، Y. P. (Y. در روش هاى دارو درمانى نيز استفاده از متيل فنديت اغلب مورد استفاده است (به عنوان مثال، ريتالين، كنسرت، اكاسيم، مديكينت). با اين حال، دى آمتدامينه و همجنين غير روان كردانها مانند اتوو كستين و كوانفاسين نيز تجويز مى شوند (فرانكو و بويتلار، · (1).

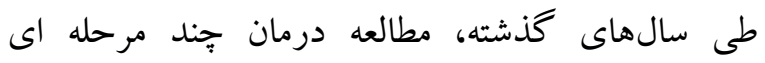
كودكان مبتلا به اختلال نقص توجه / بيش فعال و و مطالعات ييخيرى (به اصطلاح مطالعات MTA) تحقيقات

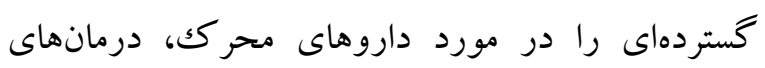
رفتارى، تركيب آنها و مراقبت از جامعه انتخاب شده ارائه كرده است. نتايج نشان مىدهد كه هر دو روش استفاده از داروى هاى محركك و رفتار درمانى و يا درمان تر كيبى در كوتاه مدت از مزاياى بالينى روشنى برخوردار

\footnotetext{
'- Attention Deficit Hyperactivity Disorder
} 
علائم اصلى اختلال نقص توجه / بيش فعالى بزر گسالان

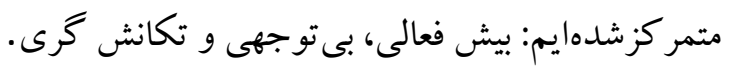
با اين حال، مهم تر از همه اينها كه نشان از لزوم تحقيقات

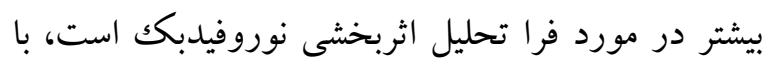
توجه به اينكه كاربرد :بروتكلهاى تازه تأسيس

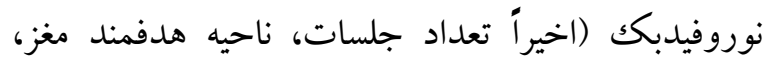
يارامتر انتخاب شده مغز، مكانيسم كار) علاوه بر آن (استانداردهاى توافق شده) مناسب و آموزش در زمينه نوروفيدبك داراى گوناكونى زيادى بوده و در كشور ما توان هم روشهاى مختلف مورد توجه قرار گرفته است؛ بنابر اين يثزوهش حاضر با رويكردى متفاوت به فرا تحليل

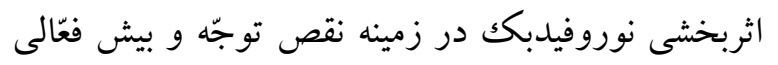

$$
\text { توجه مى بيردازد. }
$$

\section{روش}

در اين بثزوش از روش فرا تحليل استفاده شده است. در فرا تحليل اصل اساسى عبارت است از محاسبه اندازه اثر براى تحقيقات مجزا و بركرداندن آنها به يكك ماتريس مشتر كى (عمومى) و آنكاه تر كيب آنها براى دستيابى به ميانخين تأثير. اندازه اثر نشان دهنده ميزان يا درجه حضور اندر يديدهاى در جامعه است. حجم اثر مفهوم اصلى در فرا

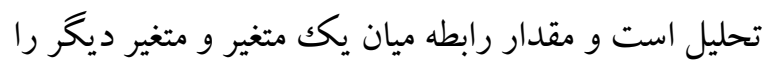
به شيوه استاندارد نشان مىدهد. جامعه آمارى مطالعه حاضر عبارت است از تمام يُّوهشهاى انجام و جّاب شده در رابطه با تأثير نوروفيدبك در كاهش علائم اختلال نقص توجّه و بيشفعالى كه از لحاظ روش شناسى (فرضيه سازى، روش تحقيق، جامعه، حجم نمونه و روش نمونه گيرى، فرضيه آمارى، روش تحليل آمارى و صحيح
مستقيماً مكانيسم عصبى اساسى شناخت و رفتار را تغيير دهد (كيرت و همكاران، 19 (Y). بيشنهاد شده است كه نوروفيدبك مبتنى بر اصول تهويه عمل و يادگيرى مهارتهاى رويهاى است. با توجه به اين مكانيسمهاى ياد گيرى، انتظار مى رود كه نورويلاستيسيته در طول آموزش نوروفيدبك يا از طريق انعطافيذيرى هبيان يا انعطافيذيرى ضد هبيى / هوموستاتيك انجام

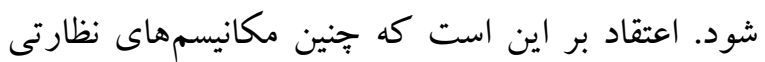
ذاتى مانع از فعاليتهاى شديد مغز مانند نقاط قوت پاتولوزيكى بالا يا بِيين سينايسى يا حالت هاى نوسانى مىشوند (كيرت و همكاران، 19 •r). اگرجهه در مورد اثربخشى نوروفيدبك مطالعات متعددى

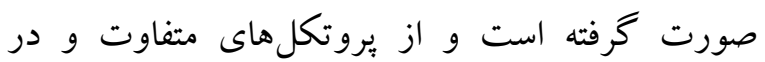
موقعيتهاى متعدد استفادهشده است، با اين وجود، مطالعات محدودى به صورت فرا تحليل وجود دارد و ما مشاهده كرديم كه هيج فرا تحليل كمى در اين زمينه تابه امروز انجام نشده است. تاكنون مطالعات مختلف حاكى از آن است كه نوروفيدبك در كاهش علائم اختلال نقص توجه / بيش فعالى مؤثر بوده است؛اما ميزان تأثير

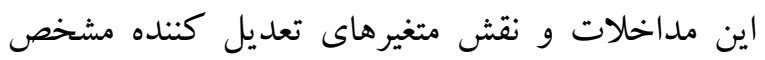
نيست؛ بنابراين، يك متآناليز به عنوان روشى قدرتمند براى ادغام بسيارى از تحقيقات و تعيين اثربخشى كلى آنها مؤثر است. اين روش تجزيه و تحليل به ما اجازه مىدهد تا به برخى از موضوعات مطرح شده بيردازيم و اندازه اثر - از اين رو، ارتباط بالينى- اين روش ها را بـ آبه روش كمى آزمايش كنيم. همانطور كه قبلاً نيز اشاره شد، بيماران اختلال نقص توجه / بيش فعالى علائم مداوم عدم توجه، تحريكك يذيرى و بيش فعالى دارند؛ بنابراين، در اين فرا تحليل، ما بر اثربخشى درمان نوروفيدبك بر 
حجم نمونه، ابزار بيزوهشى و روش تحقيق مناسب در بازه زمانى ههץ| تا يه"ا بودند (دليل انتخاب بازه زمانى سه سال كذشته در جهت سهولت دسترسى به منابع جديد و به روز است)، انتخاب شدند (جدول (). جهت گردآورى دادهها از يكك فرم تدوين شده استفاده گرديد. شكل 1 فرايند غربالكرى و انتخاب مطالعات را نشان مىدهد.
بودن محاسبات آمارى) از شرايط لازم برخوردار بوده و در بازه زمانى سه سال اخير منتشر شده اند. با استفاده از كليد وازههاى نوروفيدبك و اختلال توجه و جستوجو در سايتهاى مخيران، SID، سيويليكا و نورمخز انجام گرفت و مطالعات گوناكونى بررسى شد كه نهايت ·ل مقاله كه داراى جامعه، روش نمونه گيرى،

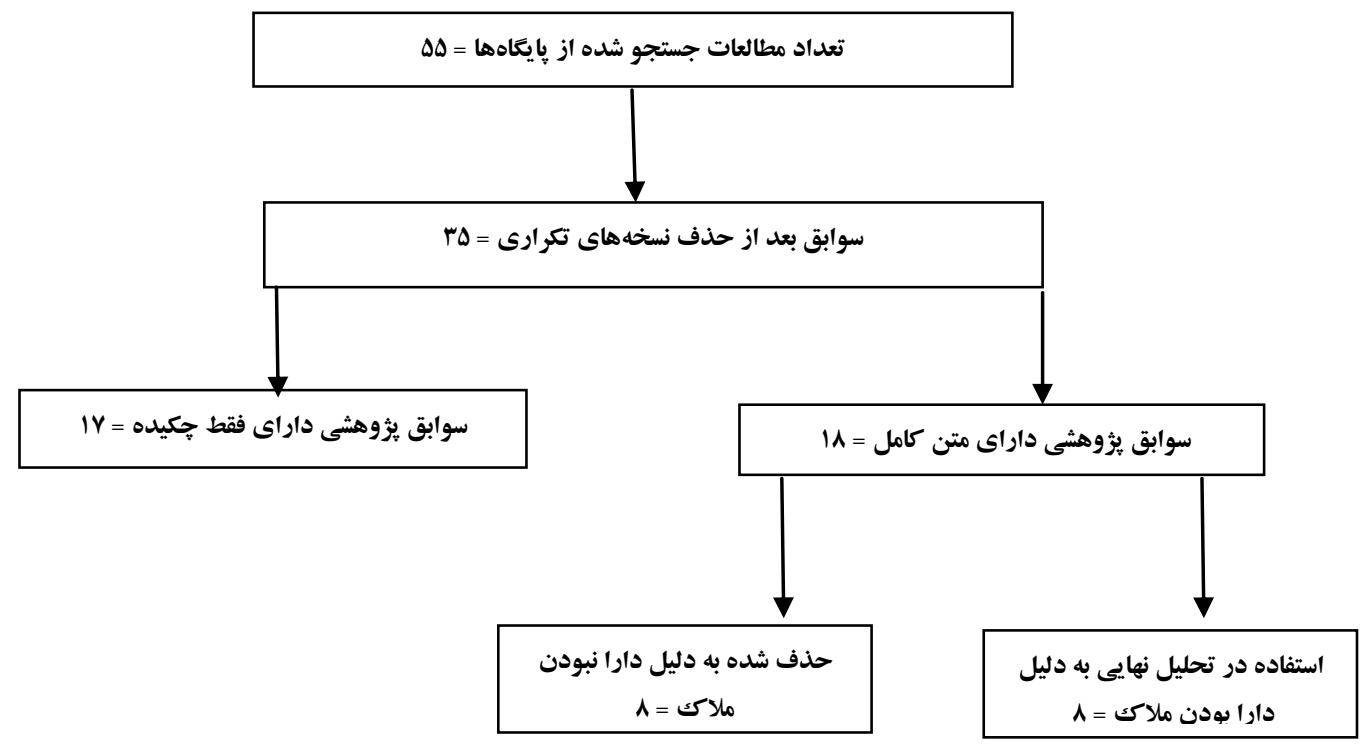

شكل ا فرايند غربالكرى و انتخاب مطالعات

روش محاسبه فرا تحليل، بر اساس مراحل فرا تحليل كوهن 'انجام مى گردد و به منظور ميزان اندازه اثر از نرمافزار CMA-2 استفاده خواهد شد. - اه

\begin{tabular}{|c|c|c|c|c|}
\hline 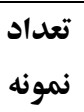 & ئزوهشكر & عنوان & سال & رديف \\
\hline$r$. & افتاده حال و موحدى & اختربخشى درمان نورو فيدبك بر بهبود كاركردهاى اجرايى در كود كان با & 1790 & 1 \\
\hline r. & اسبقى و همكاران & 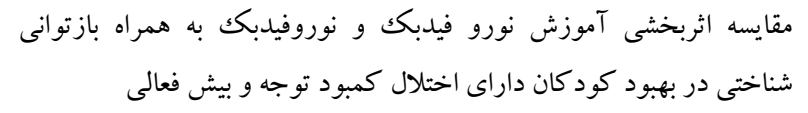 & 1790 & $r$ \\
\hline f. & غريبى و همكاران & هاي اختلال نقص تو جنه / بيش فوزالى خودتليمى كلامى و نوروفيدبكك بر كاهش نشانه & 1799 & $r$ \\
\hline
\end{tabular}

1. Cohen

مجله روانشناسى و روان يزشكى شناخت، سال هفتم، شماره Y، 94-VA Ir99، 


\begin{tabular}{|c|c|c|c|c|}
\hline fo & فرهمند،ربانى و يور فراشاه & و مقايسه اثربخشى نورو فيدبك، ريتالين و تركيب آنها در بيشرفت تحصيلى اختلال نقص توجه بيش فعالى كود كان & $1 \pi 91$ & f \\
\hline$r$. & حسن شاهى و يوسفى & مستمر مود كان نارسايى توجه / بيش فوز نورو فيدبك بر خط يايه الكتروانسفالو گرافى كمى و توجه & Irq1 & $\Delta$ \\
\hline $1 \cdots$ & عليدادى ، ستوده و كرمى & اثربخشى توانبخشى شناختى و نورو فيدبك بر بهبود حافظه كارى كود كان & IrqA & $q$ \\
\hline YF & حجه فروش و همكاران & 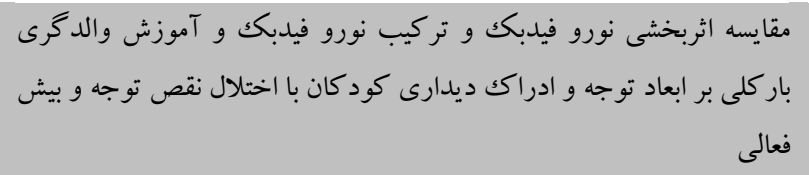 & Irq1 & $\checkmark$ \\
\hline$r$. & طيك نسب، شيخ و حمايت & فزأثير آموزش نورو فيدبك بر علائم كودكان مبتلا به اختلال نارسايى توجه / & Irag & $\wedge$ \\
\hline fD & طيك نسب، شيخ و حمايت & 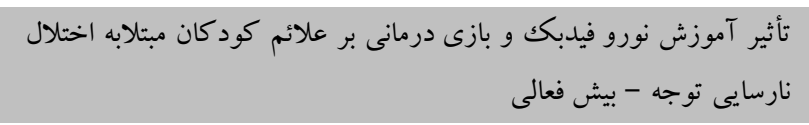 & Iras & 9 \\
\hline rF & قاسم زاده و همكاران & 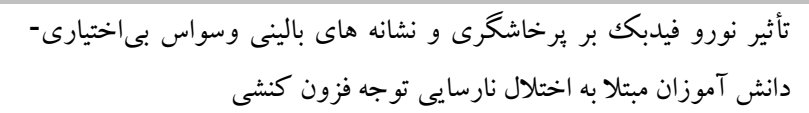 & Iras & 1 \\
\hline
\end{tabular}

تأثير. روش به كار گرفته شده در اين فرا تحليل تركيب اندازههاى اثر جهت بررسى ميزان يا درجه حضور متغير مورد بررسى و مشخصه آمارى كوهن است كه توسط ميرك برد CMA-2

\section{يافته ها} بروسى مضروضه همتنى مطالعات انجامشاهد

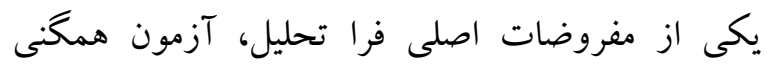
مطالعات است كه بهمنظور بررسى اين مفروضه از آزمون

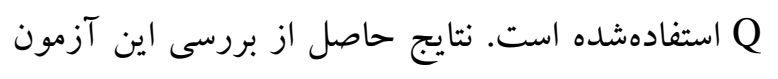
در جدول ب ارائه شده است.
در فرا تحليل، ابتدا موضوع انتخاب مىشود. سبس مسئله فرموله شده و مطالعاتى جمع آورى مىشوند كه با موضوع مرتبط بوده و همخى فرضيه يكسانى را بررسى فردى كردهاند. مشخصههاى مطالعات كدگذارى و استخراج شده، آمارهها و ميانكين و ساير دادههاى آمارى به اندازه اثر تبديل مىشود. در نهايت، اندازه اثرها با هم تركيب شده و اندازه اثرهاى تركيب شده، تفسير مىشود. به بيانى روشنتر و دقيقتر در فرا تحليل اصل اساسى عبارت است از محاسبه اندازه اثر براى تحقيقات مجزاو و بركرداندن آنها به يك ماتريس مشترك (عمومى) و و

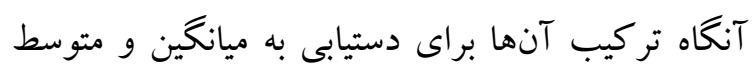

\begin{tabular}{|c|c|c|c|c|}
\hline I-Squared & سطح معنى دارى & درجه آزادى & مقدار آزمون (Q) & شاخص آمارى \\
\hline १1/A১. &.$/ .1$ & 9 & $11 \cdot / 4 M F$ & نتيجه \\
\hline
\end{tabular}


درصد نزديكتر باشد، نشاندهنده ناهمخنى بيشتر اندازه اثر بززوهشهاى اوليه است. نتايج حاصل از ضريب

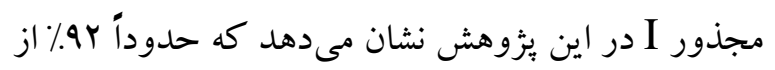
تغييرات كل مطالعات به ناهمخنى آنها مربوط است. درواقع اين آزمون به ما مى گويد كه اندازه اثر نوروفيدبكك بر علائم نقص توجه و بيش فعالى، به لحاظ ويز كى ها و مشخصات مطالعات متفاوت هستند.

نمود/ر قيفى نمودار قيفى از رايجترين روشهودا بهمنظور بررسى خطاى لمايج انتشار است. در شكل شماره (، وضعيت سو گيرى انتشار مقالات، با استفاده از نمودار قيفى ارائه گرديده است.

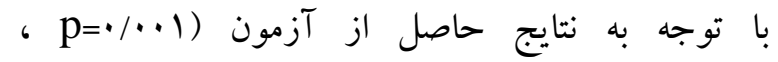

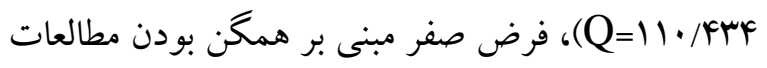
انجام شده رد و فرض ناهمگ نيى ميان يزوهشها تأييد مىشود. به بيانى ديخر، ميزان شاخص Q نشاندهنده

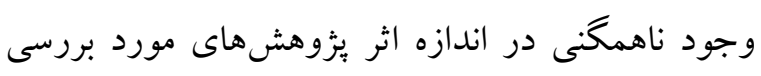
است؛ اما از آنجا كه اين شاخص به افزايش تعداد اندازه اثر حسّاس بوده و با افزايش تعداد اندازه اثر توان اين

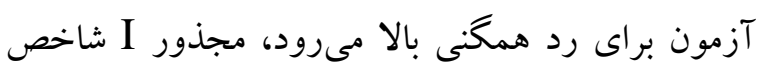
ديخرى است كه به همين منظور مورد استفاده قرار مى گيرد. ضريب مجذور I داراى مقدارى از صفر تا

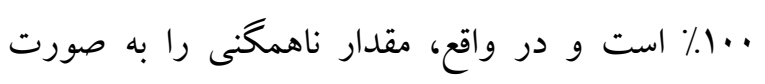
درصد نشان مىدهد. هر جه مقدار اين ضريب به ...

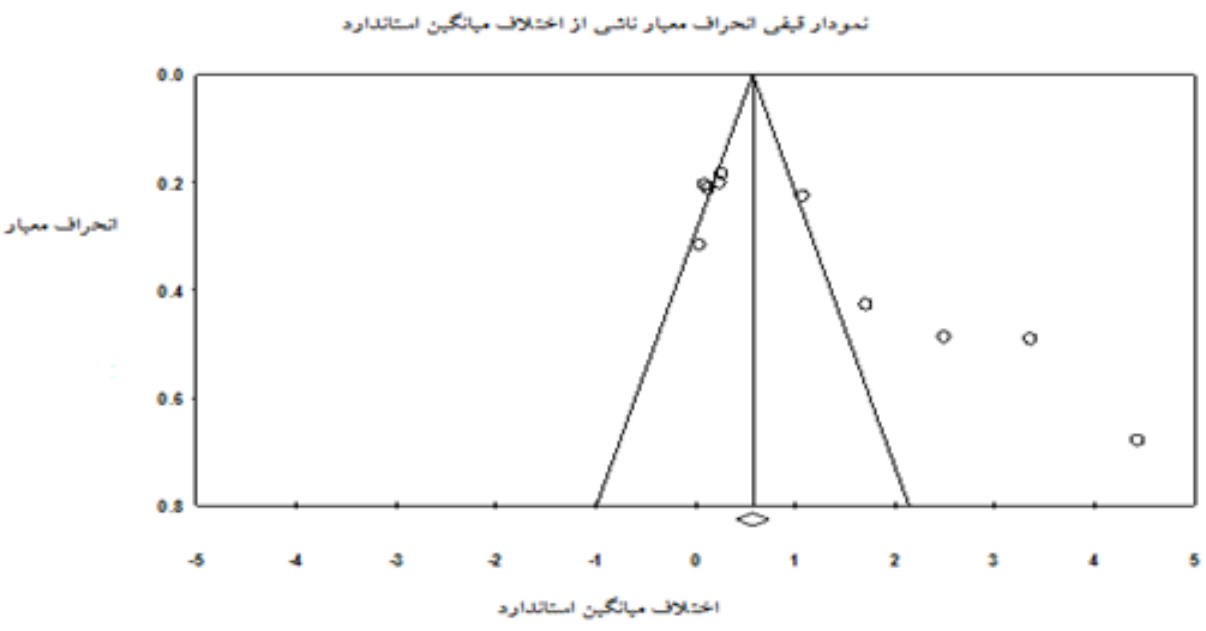

نمودار ا نمودار قيفى شكل فرا تحليل

نمودار و عدم سو گيرى انتشار و فرض خلاف (H1)، بيانگر عدم تقارن نمودار قيفى و سو گيرى انتشار است. بر اين اساس، مىتوان گفت كه مطالعات داراى سو گيرى

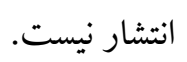

نتايج همبستَسى رتبهاى بِكَ و مُزُوملدار
نتايج حاصل از نمودار قيفى وارونه تقريباً تداعى كنده تقارن نسبى مطالعات انجامشده است؛ اما قضاوت صريحى در اين مورد نمى توان انجام داد و بايد براى اين منظور از آزمونهاى آمارى مربوطه (روش رگر ديونى

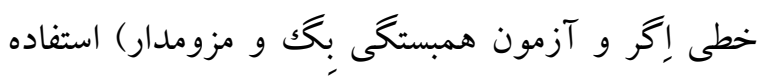
شود. در اين روش فرض صفر $)\left(H_{0}\right)$ بيانخر متقارن بودن مزون 
سو گيرى انتشار باشد، انتظار اين است كه در ارتباط با اندازه اثر بزرگكتر، خطاى استاندارد بيشتر مشاهده شود.

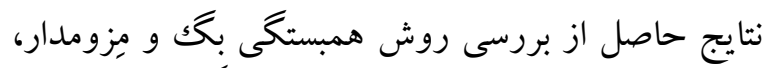
بهنظور بررسى سو گيرى به شرح جدول باست.
آزمون همبستخى رتبهاى بِك و مِزومدار، همبستگى رتبهاى (تاو كندال) بين اندازه اثر استاندارد و واريانس اين اثرها را مشخص مى كند. مقدار صفر در اين ضريب، دليل بر نبود رابطه بين اندازه اثر و دقت است و انحر اف از صفر كوياى وجود رابطه است. اگر عدم تقارن ناشى از

\begin{tabular}{|c|c|c|c|}
\hline سطح معنى دارى & Z-Value & مقدار ضريب كندال (tau) & شاخص آمارى \\
\hline.$/ \cdot 1$ & $9 / 949$ &.$|\Lambda|$. & نتايج \\
\hline
\end{tabular}

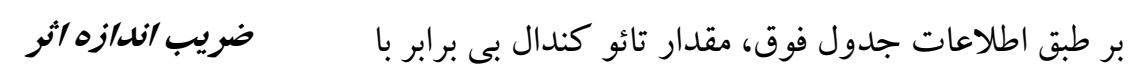

ميزان تأثير همخرايى تحقيقات انجام شده در زمينه تأثير نورو فيدبكك در كاهش علائم اختلال نقص توجّه و بيشفعالى جقدر است. بر اساس بررسىهاى انجام شده در نهايت ·1 مطالعه كه امكان تركيب داشتند انتخاب شده و تحليل انجام گرفت:

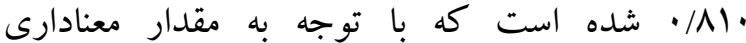
(P=•/・1) اثر و دقت رابطه وجود دارد؛ اما اين رابطه معنادار نيست و فرض صفر مبنى بر متقارن بودن نمودار قيفى و عدم سو گيرى انتشار در مورد مطالعات رد مى گردد.

\begin{tabular}{|c|c|c|c|c|}
\hline سطح معنادارى & ارزش z & اندازه اثر & نام مطالعه & رديف \\
\hline$\cdot / Y Y I$ & 1/YrY & - MAF & افتاده حال و موحدى & 1 \\
\hline.$/ 199$ &.$/ I T V$ &.$/ .4$. & اسبقى و همكاران & $r$ \\
\hline.$/ \cdot 1$ & $r / \cdot \cdots$ & $1 / \mathrm{V} \mid$ & غريبى و همكاران & $r$ \\
\hline.$\cdot \cdot 1$ & G/NFT & $r / r \Delta Q$ & فرهمند،ربانى و يور فراشاه & r \\
\hline.$/ 1 \Delta r$ & $1 / 4 \pi$ & . TS4 & حسن شاهى و يوسفى & $\Delta$ \\
\hline .1944 & $\cdot / 9 \vee 4$ & $.1 .9 V$ & عليدادى، ستوده و كرمى & 9 \\
\hline$\cdot / D F G$ & $\cdot 19 \cdot r$ & $\cdot / \mathrm{TV}$ & حجه فروش و همكاران & $\checkmark$ \\
\hline$\cdot / \cdot 1$ & $\Delta / I Y F$ & $r / F 9 \Delta$ & نيك نسب، شيخ و حمايت طلب & $\wedge$ \\
\hline.$/ \cdot 1$ & q/or. & F/FTT & نيكك نسب، شيخ و حمايت طلب & 9 \\
\hline$\cdot / \cdot 1$ & $F / V$. & $1 / \cdot \sqrt{ } 9$ & قاسم زاده و همكاران & $1 \cdot$ \\
\hline$\cdot / \cdot \cdot 1$ & 9/994 & $\cdot / \Delta V^{F}$ & كل & 11 \\
\hline
\end{tabular}

بيشفعالى با تأكيد بر بزوهشهاى ايرانى، با توجه به مدل ثابت اندازه اثر محاسبه شد كه بعد از تركيب مطالعات
در تمام تحقيقات موجود در نمونه در حوزه تأثير نوروفيدبك در كاهش علائم اختلال نقص توجّه و 


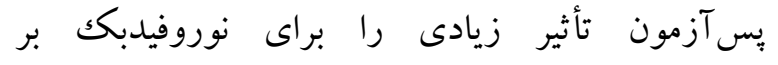
تكانش گرى و بىتوجهى و اندازه متوسط براى بيش فعالى يافته اند. بعلاوه، مطالعات متعددى نيز گزارش بـ كرده اند كه اثرات آموزش نوروفيدبك در طى 4 ماه

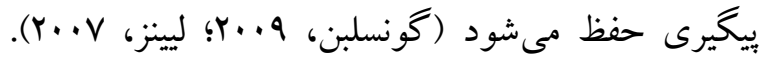
براى توضيح اين يافته ها، مىتوان كفت كه NF با هدف دستيابى به خودكنترلى بر روى برخى از فعاليتهاى

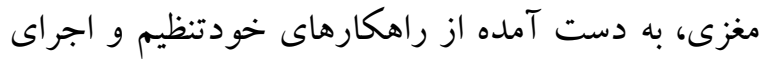
اين مهارتهاى خودتنظيم در زندگى روزمره است. در آموزش تتا / بتا، كودكان ياد مى گيرند كه در گروه تتا

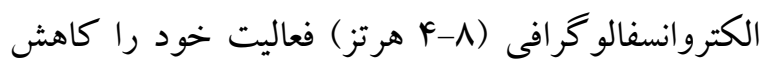

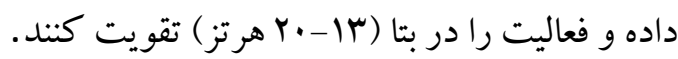

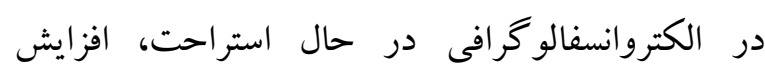
فعاليت موج آهسته (تتا) و / يا كاهش آلفا نسبى (^-ربا هرتز) و فعاليت بتا در جندين مطالعه در مورد كود كان مبتلا به اختلال نقص توجه / بيش فعال ززارش شده است

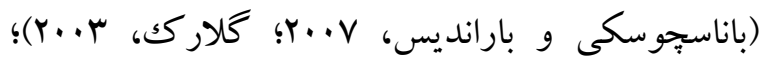

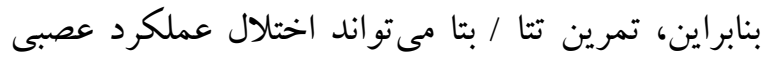
اساسى را هدف قرار دهد؛ به عبارت ديخر، نوروفيدبك لهريك مىتواند ابزارى براى افزايش حالات خاص شناختى يا توجه باشد (حالت هوشيار و متمركز؛ اما آرام در تمرين تتا / بتا)، صرف نظر از انحرافات عصبى فرضى

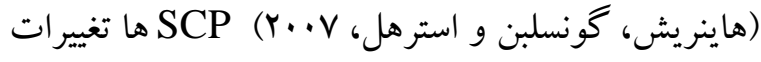
فعاليت الكتريكى قشر مغزى هستند كه از جند صد ميلى ثانيه تا جند ثانيه هستند. تصور مىشود آنها نمايانكر بسيج هاى كو تاه مدت وابسته به وظيفه منابع يردازش قشر مغز هستند. در حالى كه SCP هاى منفى نشان دهنده افزايش برانگيختكى هستند (به عنوان مثال در حين آماده سازى رفتارى يا شناختى)، SCP هاى مثبت باعث كاهش
مقدار اندازه اثر كلى اين ·1 مطالعه تحت مدل ثابت برابر با DVF/ به دست آمد كه با اطمينان در فاصله حد

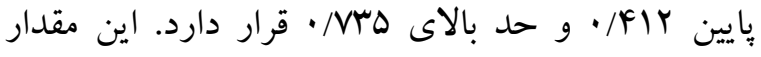
اندازه اثر طبق تفسير ملاكك كوهن مقدار بالايى است. مقدار Z مربوط به اين اندازه اثر برابر با 9/994است كه با احتمال كمتر از ه•/ ( بنابر اين مىتوان نتيجه كيرى كرد كه نتايج بهدست آمده از تركيب اين · ا مطالعه داراى اندازه اثر معنادارى مىباشند. از ميان 9 ئزوهش انجام شده بيشترين اندازه اثر محاسبه شده مربوط به بززوهش شماره 9 (يزٔوهش دومنيك نسب، شيخ و حمايت طلب) است كه داراى اندازه اثر سمF/F است و بثوهش شماره F (فرهمند، ربانى و يور فراشاه)

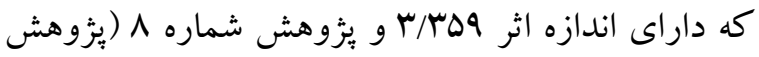
اول نيك نسب، شيخ و حمايت طلب) كه داراى اندازه اثر به ميزان \$ Y Y است در رتبه بعدى قرار دارد. روش آمارى فرا تحليل نشان داد كه اندازههاى اثر براى آزمايش يكك فرضيه خاص تركيب شدهاند؛ بنابراين، مىتوان تعدادى تحقيق را با استفاده از همان متغير انجام داد و نتايج را مىتوان در يكك تحقيق واحد تركيب كرد

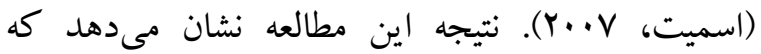
نوروفيدبكك تأثير زيادى در عدم توجه، تحريك يذيرى،

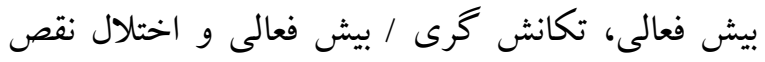
توجه / بيشفعال در بزر كسالان دارد. نتايج اين فرا تحليل

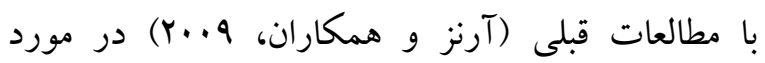
اثربخشى درمان نوروفيدبك در كود كان مبتلا به اختلال نقص توجه / بيش فعال مطابقت دارد. هر دو مطالعه و بررسىهاى آينده نگر با استفاده از طرح بيش آزمون و 
تاميسون، ب...Y). فر آيند تهويه عملياتى شامل اصلاح رفتار است كه با استفاده از آن عواقب يكك عمل احتمال رفتار در آينده را مشخص مى كند. وفور رفتارهاى تقويت شده مثبت در آينده افزايش مىيابد در حالى كه رفتارهايى كه تقويت مىشوند منفى باشند نايديد مىشوند

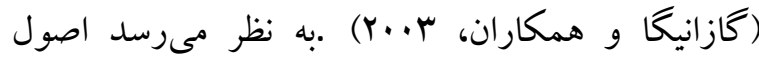
شرطبندى فاكتور عامل مهمى در توانايى نوروفيدبك براى ايجاد تغيير در الكتروانسفالو كرافى است؛ بنابراين

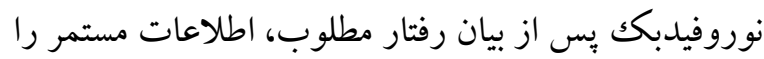
براى فرد فراهم مى كند تا اين اطلاعات منجر به عود مجدد آن رفتار شود.

\section{نتيجه كيرى}

نتايج اين فرا تحليل، از ارزش و اثربخشى درمان نوروفيدبك در كودكان مبتلا به اختلال نقص توجه / بيش فعال يشتيبانى مى كند. مىتوان نتيجه كرفت كه درمان نوروفيدبك مىتواند به افراد مبتلا به اختلال نقص توجه / بيش فعال در تنظيم فعاليت امواج مغزى كمكك كند و از اين رو، مشكلات تحريككيذيرى، بى توجهى و

$$
\text { بيش فعالى آنها را بهبود بخشد. }
$$

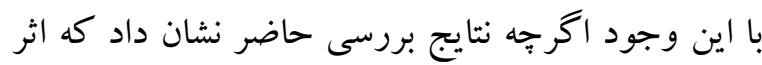
تركيبى يُوهشهاى انجام شده بر اساس معيار ارزيابى كوهن، اثر بالايى بود ولى با اين وجود بيزوهشها اثرات

$$
\text { ناهمخونى را گزارش كرده اند. }
$$

صرف نظر از تأثير معنادار نوروفيدبك در كاهش علائم اختلال نقص توجّه و بيش فعّالى ناهمگُونى متعدد در يثوهشهاى مختلف را مىتوان با توجه به نتايج

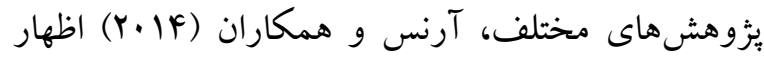
داشت كه انجام كمتر از ·r جلسه نوروفيدبك منجر به
تحريك قشر شبكه هاى عصبى زيرين (به عنوان مثال در هنگام مهار رفتارى) مىشوند (بيرمومر، •199).

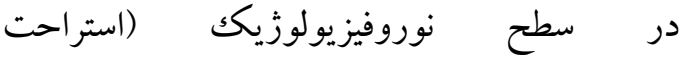

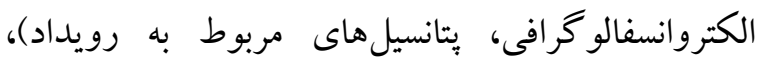
رابطه خاصى بين بهبود رفتار و آموزش تتا / بتا و كCP وجود دارد (به عنوان مثال ارتباط بين كاهش فعاليت تتا و كاهش علائم اختلال نقص توجه / بيشفعالى) (كونسلبن

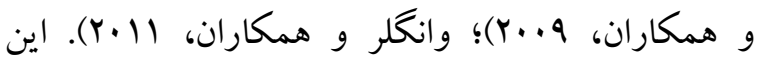
اثرات نوروفيزيولوزيكى منجر به دركك بهتر مكانيسمهاى اساسى اثربخشى آموزش نوروفيدبك مىشود. از طرف ديخر، بهبود قابل توجهى در كاهش علائم بيش فعالى در الر طول تمرين نوروفيدبك ممكن است بيانكر فرايندهاى توجه قابل توجه در كاهش علائم بيش فعالى باشد. اين امر به اين دليل است كه مكانيسمهاى خودتنظيم امواج مغزى كه در عملكرد طبيعى مغز نقش اساسى دارند، توجه را بهبود مى بخشند و بيش فعالى را در دانش آموزان

$$
\text { كاهش مى دهند (دموس، ه. - (Y). }
$$

مغز انسان به تنهايى قادر به بهبودى است و توانايى ياد گيرى يا رهاسازى مكانيسمهاى موج تنظيم فشار خود مغز را دارد كه نقش مهمى در عملكرد طبيعى مغز دارند

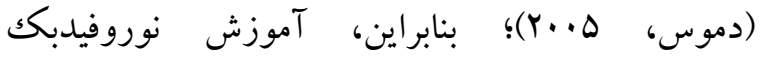
مكانيسمهاى اساسى تنظيم خود را تقويت مى كند تا به طور مؤثر كار كند. اين سيستم آموزشى با بازخورد به مغز در مورد آنجه فرد در جُند ثانيه اخير انجام داده است و اينكه ريتم بيوالكتريكك مغز عادى جيست مغز را به تصحيح، اصلاح و حفظ فعاليت مناسب ترغيب مى كند. مبناى نظرى نوروفيدبك مربوط به قانون اثر و نظريههاى

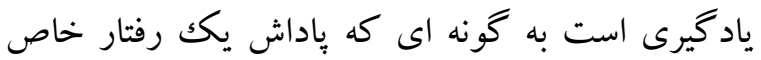
احتمال بروز عود رفتار را افزايش مىدهد (تاميسون و 
اين طريق عامل تبينى قابل توجهى تشكيل نمىدهند. اين نتيجه، با اين وجود، از يكك استراتزى تر كيبى و شخصى لئى (ارائه يروتكلهاى شخصىسازى شده بر اساس فنوتيبها) براى بهبود بيشتر عملكرد جلو گيرى نمى كند،

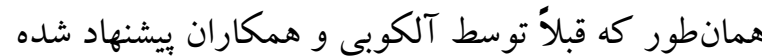

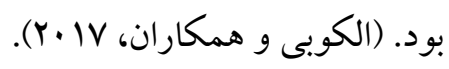

عوامل مختلفى با هر سه روش با همان جهت تأثير انتخاب شدند: كيفيت نوروفيدبك، طول مدت درمان و احتمالاً ناديده گرفتن مجراى درمان. اول، تجزيه و تحليل ما نشان داد كه اجراى نوروفيدبك در شرايط مناسب منجر به نتايج بهترى مىشود. اين را مىتوان با اين واقعيت توضيح داد كه كيفيت بهتر سيخنال، استخراج دقيقتر الكوهاى نوروفيدبك مرتبط با اختلال نقص توجه / بيش فعال را امكانيذير مى كند و از اين رو منجر به يادگيرى و اثر بخشى درمانى بهتر مىشود. با اين حال، ارزيابى كيفيت سخت افزار نوروفيدبك (مانند تقويت كننده مورد استفاده) دشوار است؛ زيرا اطلاعات كمى در اين مطالعات ارائه شده است. اين امر نياز به مراقبت بيشتر در مطالعات آينده دارد كه بايد در ارزيابى و ززارش كيفيت

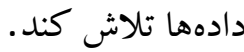
در مرحله بعد، به نظر مىرسد كه هرجه دوره درمان طولانى تر باشد، كار آيى آن نيز كمتر مىشود. اين ممكن است با ميزان درگيرى با مداخله نوروفيدبك توضيح داده شود: شايد دركير شدن با يك دوره طولانى از درمان دشوار باشد. با اين حال، تعيين كميت دشوار است؛ زيرا هيج يرسشنامه ارزيابى دقيق در مورد كودكان ايجاد نشده است يا اين اطلاعات ارائه نشده است. نكته جالب براى تحقيق است؛بنابر اين ما از مطالعات آينده دعوت مى كنيم تا در صورت امكان آن را به اشتراكك بخذارند.
اثرات كمترى خواهد شد. به همين ترتيب، ورنون و همكاران (Y...F) مشاهده كرد كه تغييرات مثبت در r. الكتروانسفالو گرافى و عملكرد رفتارى بعد از حداقل جلسه رخ داده است. با اين حال، انريكوييز و گيرت و و همكاران (Y.IV) تأكيد كرد كه تعداد جلسات بايد به دقت انتخاب شود تا از (سبقت گرفتن) جلو گيرى شود. اين واقعيت كه تعداد جلسات به عنوان يكك عامل مؤثر مثبت مشخص نشده ممكن است با حضور تنها دو نقطه داده با . r جلسه يا كمتر توضيح داده شود. به نظر مىرسد، آستانه زمانى اثربخشى براى كليه مطالعات شامل انجام شد و شناسايى اين عامل توسط سه روش بعيد در اين مجموعه داده بعيد است. با اين حال، دو روش كه اين عامل را مشخص مى كند، توافق داشتند كه همانطور كه انتظار مىرود، هرجه جلسات بيشتر انجام شود، نوروفيدبك كار آمدتر خواهد بودد. جالب اينجاست كه ميندر و همكاران (YN) مىدهد كه محل موضوع آموزش نوروفيدبك همجنين ممكن است يكك عامل مهم در اثربخشى بالينى باشد. با اين حال، اين مطالعه اخير انجام شده است (ميندر و

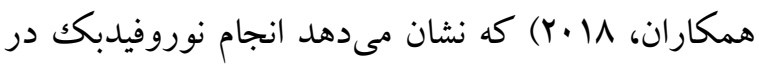
مدرسه يا در كلينيكك تأثير معنىدارى در يّاسخ به درمان

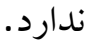
نوع بروتكل نوروفيدبك با هيج روشى مشخص نشده و به نظر نمىرسد كه بر نتايج NFB تأثير بخذارد. اين اهميت

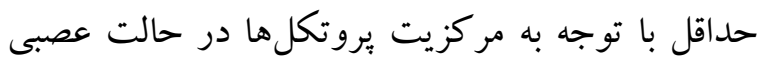

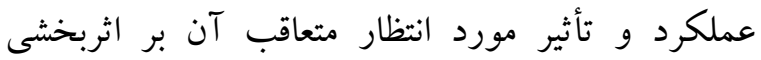
درمانى، ضد شهودى است. توضيح احتمالى براى اين نتيجه اين است كه اين يروتكلها براى جمعيتى كه به آنها بيشنهاد شدهاند به همان اندازه كار آمد بودهاند و از 
آكاهى خارج مىشوند. توجه انتخابى (متمر كز ) به فرايند تمركز منابع بر جنبه هاى خاصى از همه درون دادهها

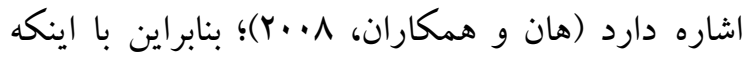
توجه شامل مداليتهاى مختلفى است؛ اما مىتوان كفت كه آموزش نورو فيدبك باعث ارتقاى عملكرد توجه مىشود. در اين مطالعه، ما به دنبال تعيين اين موضوع بوديم كه آيا در مطالعات انجام شده همخى نتايج بين مطالعات در استفاده از برنامه آموزشى نورو فيدبك در بهبود توجه در كود كان داراى مشكلات توجه وجود دارد. نتايج يزوهش حاضر نشان مىدهد كه آموزش نوروفيدبك در كل و بر اساس نتايج تر كيبى بزٔوهش ها مى تو اند باعث بهبود توجه كودكان و عملكرد اجرايى قشر جلوى آنها (به عنوان مثال، مهار پِاسخ، تغيير توجه، حافظه كارى) در يكك شرايط غير بالينى شود. علاوه بر اين، مطالعه حاضر اعتبار معنادارى از آموزش نورو فيدبك بعنوان ابزارى براى بهبود عملكرد شناختى كود كان، نه تنها به واسطه مقياس هاى ارزيابى رفتارى بلكه با استفاده از اقدامات بيشتر مغز فراهم كرده است. مطالعه حاضر از محدوديت هاى زير برخوردار بود. اول، تعداد مقالات مورد بررسى مربوط به

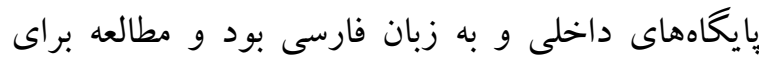
شرايط مختلف و در زبانهاى مختلف، نتايج جامعترى مى تواند داشته باشد. بر اين اساس، اندازه نمونههاى كوجٍك ممكن است اندازه اثر آمارى را تحت تاير قرار دهد؛ بنابراين، مطالعات بيشتر به تعداد بيشترى از مقالات نياز دارد تا بتوانند تكليف تصادفى را انجام دهند و نياز به تأييد مجدد را برآورده سازند. محدوديت دوم كوتاه بودن نسبى دوره زمانى ارزيابى بود. اين ممكن است

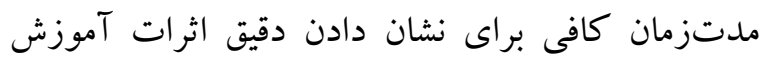

تبيين در رابطه با اثربخشى نورو فيدبك بر بهبود توجه اين است كه مكانيسم زيربنايى روش نورو فيدبك همان نظريه شرطىسازى عامل است، بهطورى كه اخر تغيير محرك (دامنه امواج مغزى) بر مبناى قرارداد از بيش تعيين شده با بيامد مطلوب (حركت تصاوير ويديوئى يا

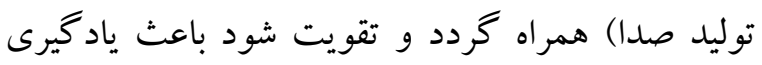
خو اهد شد و اين يادكيرى زمانى مؤثرتر خواهد بود كه از محر كهاى سادهتر كه منجر به دريافت تقويت مىشود، شروع و سيس به سمت محر كهاى بيجيدهتر حركت كرد؛ بنابراين روش نورو فيدبك بهعنوان شيوه ناظر بر ارائه اطلاعات به فرد كمكك مى كند تا در آينده رفتار مناسب نشان دهد؛ در نتيجه با اين اطلاعات دانش آموز ياد مىكيرد تا رفتار مناسب را در جهت مطلوب تغيير دهد كه اين امور باعث افزايش توجه بِايدار مىشوند.

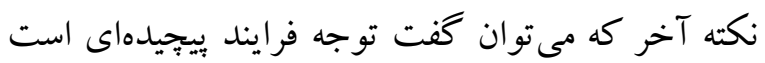
كه بهطورمعمول به مجموعه گستردهاى از مهارتها، فرايندها و وضعيتهاى شناختى اطلاق مىشود .بر اساس شواهد موجود توجه مىتواند مداليتهاى بينايى، شنوايى و لامسه را به خود اختصاص دهد. امروزه توجه بهطور روزافزون، سو گيرى در يردازش عصبى اطلاعات تلقى مىشود. محرككها براى بازنمايى و حضور در ميدان

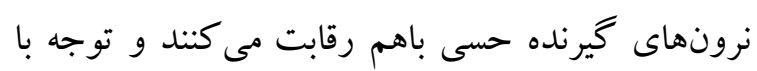
ايجاد سو گيرى در اين بازنمايى باعث مىشود .فقط محر ككهاى خاصى موردتوجه قرار گيرند ـمفهوم توجه بهطور سنتى با نظريه منابع و ايده اصلى آن، يعنى محدود بودن ظرفيت موجود زنده براى بردازش

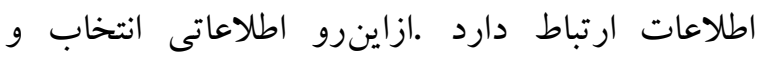
يردازش مىشوند كه موردتوجه قرار كيرند، درحالى كه درون دادههايى كه موردتوجه قرار نخرفتهاند از حيطه 
adults with attention-deficithyperactivity disorder. International Joumal of Psychophysiology, 70(3), 176-83.

Coben R, Hammond D. (2018). Corydon, Ams Martijn. 19 Channel Z-Score and LORETA Neurofeedback: Does the Evidence Support the Hype? Applied Psychophysiology and Biofeedback, 44(1):1-8.

Daly BP, Creed T, Xanthopoulos M, Brown RT. (2007). Psychosocial treatments for children with attention deficithyperactivity disorder. Neuropsychol Rev. ,17(1):73-89.

DeBeus R, Kaiser D. (2011). Neurofeedback with children with attention deficit hyperactivity disorder: a randomized double-blind placebocontrolled study. In: Coben R, Evans J, editors. Neurofeedback and neuromodulation: techniques and applications. San Diego: Elsevier,pp. 127-152.

Demos JN. (2005). Getting started with neurofeedback. New York: WW Norton \& Company.

Engelbregt HJ, Keeser D, Van Eijk L, Suiker EM, Eichhom D, Karch S, et al. (2016). Short and long-term effects of sham-controlled prefrontal EEG-neurofeedback training in healthy subjects. Clin Neurophysiol, 127(4):19311937.

Enriquez-Geppert S, Huster RJ, Figge C, Herrmann CS. (2014). Self-regulation of frontal-midline theta facilitates memory updating and mental set shifting. Front Behav Neurosci, 8:420.

Enriquez-Geppert S, Huster RJ, Figge C, Herrmann CS. (2014). Self-regulation of frontal-midline theta facilitates memory updating and mental set shifting. Front Behav Neurosci, 8:420.

Enriquez-Geppert S, Huster RJ, Hermann CS. (2017). EEG-neurofeedback as a tool to modulate cognition and behavior: a review tutorial. Front Hum Neurosci, 11:51. 10.3389/fnhum.

Escolano C, Aquilar M, Minguey J. (2011). EEG-based upper alpha neurofeedback training improves working memory performance. Conf Proc IEEEEng Med Biol Soc, 2327-30.

Faraone SV, Buitelaar J. (2010). Comparing the efficacy of stimulants for ADHD in children

$$
\begin{aligned}
& \text { نورو فيدبك بر تغييرات فعاليت نبوده باشد. با وجود خنين } \\
& \text { محدوديتهايى، نتيجه مطالعه حاضر مىتواند معنادار } \\
& \text { باشد؛ زيرا اولين مطالعه فرا تحليل تأثير نوروفيدبك با } \\
& \text { استفاده از ابزارى كيفى بود. }
\end{aligned}
$$

\section{References}

Alegria AA, Wulff M, Brinson H, Barker GJ, Norman LJ, Brandeis D, et al. (2017). Real-time fMRI neurofeedback in adolescents with attention deficit hyperactivity disorder. Hum Brain Mapp, 38(6):3190-3209.

Alkoby O, Abu-Rmileh A, Shriki O, Todder D. (2017). Can we predict who will respond to neurofeedback? A review of the inefficacy problem and existing predictors for successful EEG neurofeedback leaming. Neuroscience, 378:155-64.

10.1016/j.neuroscience.2016.12.050.

Amold LE, Lofthouse N, Hersch S, Pan X, Hurt E, Bates B, Kassouf K, Moone S, Grantier C. (2013). EEG neurofeedback for ADHD: double-blind sham-controlled randomized pilot feasibility trial. J Atten Disord,17(5):410419.

Ams M, De Ridder S, Strehl U, Breteler M, \& Coenen A. (2009). Efficacy of neurofeedback treatment in $\mathrm{ADHD}$ : The effects on inattention, impulsivity and hyperactivity: A meta-analysis. Clinical EEG and Neuroscience, 40(3), 180-9. doi: 10.1177/155005940904000311.

Ams M, Heinrich H, Strehl U. (2014). Evaluation of neurofeedback in ADHD: the long and winding road. Biol Psychol, 95:108-115.

Banaschewski T, \& Brandeis D. (2007). Annotation: What electrical brain activity tells us about brain function that other techniques cannot tell us? A child psychiatric perspective. Joumal of Child Psychology and Psychiatry, 48(5), 41535. doi: 10.1111/j.1469-7610.2006.01681.x.

Clarke AR, Barry RJ, Heaven PC, McCarthy R, Selikowitz M, \& Byme MK. (2008). EEG in 
and adolescents using meta-analysis. Eur Child Adolesc Psychiatry, 19(4):353-364.

Gazzaniga MS, Heatherton TF, \& Veronese MAV. (2003). Psychological science: Mind, Brain, and Behavior. New York: WW Norton \& Company.

Gevensleben H, Holl B, Albrecht B, Vogel C, Schlamp $\mathrm{D}$, Kratz O, et al. (2009). Is neurofeedback an efficacious treatment for ADHD? A randomised controlled clinical trial. Joumal of Child Psychology and Psychiatry, 50(7), 7809. doi: 10.1111/j.1469-7610.2008.02033.x

Gevensleben H, Holl B, Albrecht B, Vogel C, Schlamp D, Kratz O, et al. (2009). Is neurofeedback an efficacious treatment for ADHD? A randomised controlled clinical trial. Joumal of Child Psychology and Psychiatry, 50(7), 7809. doi: 10.1111/j.1469-7610.2008.02033.x

Leins U, Goth G, Hinterberger T, Klinger C, Rumpf N, \& Strehl U. (2007). Neurofeedback for children with ADHD: A comparison of SCP and Theta/Beta protocols. Applied Psychophysiology and Biofeedback, 32(2), 73-88. doi: 10.1007/s10484-007-9031-0

Michael Borenstein LV, Hedges JPT, Higgins, \& Rothstein HR. (2009). Second Edition Guide for Comprehensive Meta-Analysis Software. Translation by delavar, ali \& ganji, Kamran. (2014). Allameh tabataba’i university. (Persian).

Minder F, Zuberer A, Brandeis D, Drechsler R. (2018). Informant-related effects of neurofeedback and cognitive training in children with $\mathrm{ADHD}$ including a waiting control phase: a randomized-controlled trial. Eur Child Adolesc Psychiatry, 27:1055-66. 10.1007/s00787-018-1116-1.

Molina BSG, Hinshaw SP, Swanson JM, Amold LE, Vitiello B, Jensen PS, Epstein JN, Hoza B, Hechtman L, Abikoff HB, Elliott GR, Greenhill LL, Newcom JH, Wells KC, Wigal T, Gibbons RD, Hur K, Houck PR. (2009). MTA Cooperative Group The MTA at 8 years: prospective follow-up of children treated for combined-type $\mathrm{ADHD}$ in a multisite study.
J Am Acad Child Adolesc Psychiatry, 48(5):484-500.

Nemati Sh, Alizadeh H. (2017). Neurofeedback Efficacy Analysis in the Treatment of Attention Deficit / Hyperactivity Disorder. Psychology of Exceptional People. 7 (28): 120. (Persian).

Ros T, Munneke M, Ruge D, Guzelier J, Rothwell J. (2010). Endogenous control of waking brain rhythms induces neuroplasticity in humans. Eur J Neurosci, 31(4):770-778.

Smith AK, Mick E, \& Faraone SV. (2009). Advances in genetic studies of attentiondeficithyperactivity disorder. Cument Psychiatry Reports, 11(2), 143-8. doi: 10.1007/s11920-009-0022-0

Sonuga-Barke EJ, Brandeis D, Holtmann M, Cortese S. (2014). Computer-based cognitive training for attention-deficithyperactivity disorder: a review of current evidence. Child Adolesc Psychiatr Clin N Am, 23(4):807-824.

Storebø OJ, Ramstad E, Krogh HB, Nilausen TD, Skoog M, Holmskov M, et al. (2015). Methylphenidate for children and adolescents with attention deficit hyperactivity disorder (ADHD) Cochrane Database Syst Rev. 11:CD009885.

Taylor E, Dopfner M, Sergeant J. (2004). European clinical guidelines for hyperkinetic disorder first upgrade. Eur Child Adolesc Psychiatry, 13(Suppl 1):i7-i30.

Thompson M, \& Thompson L. (2003). Neurofeedback treatment for autistic spectrum disorders: Review of 60 cases-principles and outcome. Applied Psychophysiology and Biofeedback, 28(4), 305-6.

Van Dongen-Boomsma M, Vollebregt MA, SlaatsWillemse D, Buitelaar J. (2013). A randomized placebo-controlled trial of electroencephalographic

(EEG) neurofeedback in children with attentiondeficithyperactivity disorder. J Clin Psychiatry, 74(8):821-827.

Vernon D, Frick A, Gruzelier J. (2004). Neurofeedback as a treatment for $\mathrm{ADHD}$ : a methodological 
review with implications for future research. $\mathrm{J}$ Neurother, 8:53-82. 10.1300/J184v08n02_04. 